\title{
Las clases medias y los desafíos de la participación: procesos de ciudadanización en la producción de ciudad (La Plata, Argentina. 2013-2015) ${ }^{1}$
}

\author{
The middle classes and the challenges of participation: processes of \\ citizenship in the production of the city (La Plata, Argentina. 2013-2015)
}

\author{
Violeta Ventura ${ }^{2}$ \\ Fecha de recepción: 19-02-2021 - Fecha de aceptación: 05-08-2021 \\ Hábitat y Sociedad (ISSN 2173-125X), n. ${ }^{\circ}$ 14, noviembre de 2021, pp. 223-241. \\ https://doi.org/10.12795/HabitatySociedad.2021.i14.012
}

\begin{abstract}
Summary
The question about the relationship between associative forms of participation and city production is the guideline of Latin American urban studies, widely studied in its intersection with popular sectors. This article seeks to link to that discussion, providing a case where the population involved belongs to the middle classes. To do this, we will analyze the process by which middle class youth collectively organized (2013-2015) in the city of La Plata (Argentina), to access urban land and, with it, a housing policy (PROCREAR). We will investigate how they built their claim on a public problem, moved within statehood and became co-producers of urban regulations (Ordinance 11094/13). Our main finding will be that the effectiveness of their practices rested, on the one hand, on factors specific to the group - broad and hierarchical networks of social relationships; collectivization of cultural capital; habituality within statehood- on the other, in the selectivity of state bureaucracies. Based on this, we will conclude that during the collective action of the middle classes in order to get involved in the production of the city, there was an active process of citizenship. The research starts from a qualitative methodological approach, using virtual ethnography, field observation and in-depth interviews as the main procedures.
\end{abstract}

\section{Key words}

Participation Mandate; City Production; Middle Classes; Citizenship Process

\section{Resumen}

La pregunta por la relación entre formas asociativas de participación y producción de ciudad es rectora de los estudios urbanos latinoamericanos, siendo ampliamente trabajada en su cruce con los sectores populares. Este artículo busca enlazarse a ella, aportando un caso donde la población involucrada pertenece a las clases medias. Para ello analizaremos el proceso mediante el cual jóvenes de clases medias se organizaron colectivamente (2013-2015) en la ciudad de La Plata (Argentina) para acceder a suelo urbano y, con ello, a una política habitacional (el PROCREAR). Indagaremos cómo construyeron su demanda en un problema público, transitaron la estatalidad y se constituyeron en co-productores es de la normativa urbana (Ordenanza 11094/13). Nuestro principal hallazgo será que la efectividad de sus prácticas radicó por un lado en factores propios del colectivo - amplias y jerarquizadas redes de relaciones sociales; colectivización del capital cultural; habitualidad al interior del Estado-y por el otro, en la selectividad de las burocracias estatales. En base a ello concluiremos que durante la acción colectiva desplegada por las clases medias a fin de producir ciudad, se dio un proceso activo de ciudadanización. La investigación parte de un enfoque metodológico cualitativo, utilizándose como principales procedimientos la etnografía virtual, la observación de campo y la entrevista en profundidad.

\section{Palabras clave}

Mandato de participación; Producción de Ciudad; Clases Medias; Proceso de ciudadanización; Producción Social del Hábitat

\footnotetext{
1 Este artículo forma parte del Proyecto I+D+i "Producción Social del Hábitat en áreas metropolitanas del Norte y el Sur Global: políticas, instituciones y movilización social (ALTERHABITAT)” Ref.: (PID2019-105205RB-100), AEI:10.130.139/501100011033, financiado por el Ministerio de Ciencia, Innovación y Universidades (España).

2 Socióloga y Doctora en Estudios Urbanos (ICO-UNGS). Becaria doctoral (2015-2020) y posdoctoral (2020-2022) del Consejo Nacional de Investigación Científica y Técnica (CONICET). Docente en la Facultad de Humanidades y Ciencias de la Educación (FAHCE-UNLP). Integrante del Grupo de Estudios Urbanos del Centro de Investigaciones Geográficas (IdIHCS UNLP/CONICET). Email: violetaventura.lp@gmail.com. ORCID: http://orcid.org/0000-0002-1561-2857.
} 


\section{Introducción}

El lugar ocupado por los movimientos vecinales y las formas asociativas de la sociedad en la producción de ciudad, es una pregunta clásica en los estudios urbanos latinoamericanos. Este tópico ha sido ampliamente trabajado en su cruce con los sectores populares. La bibliografía argentina, por ejemplo, analizó sistemáticamente los procesos de producción social del hábitat y las prácticas autogestivas promovidas por los movimientos sociales (Di Virgilio y Rodríguez, 2013; Rodríguez, 2004; Rodríguez, 2013; Zapata, 2017). Lo mismo sucede al recorrer la pregunta por cómo las formas asociativas se articulan con la implementación y diseño de políticas públicas urbanas, siendo vasta la bibliografía que analiza cómo las poblaciones beneficiarias incidieron en los procesos de implementación y también aquella que se detiene en las transformaciones que las decisiones públicas imprimen en las biografías e inscripciones territoriales de sus receptores (Cravino y Mutuberría Lazarini, 2012; Di Virgilio, 2012; Moreno, 2012; Potocko, 2015; Zapata, 2017). Asimismo, atravesando críticamente el debate en torno a la participación (Landau, 2008a; 2008b; Roffman, 2007) todos estos trabajos se preocuparon tanto por la vulnerabilidad de los sectores populares al articularse a instancias participativas vinculadas a decisiones públicas urbanas, como por las fortalezas nacidas de su capacidad organizativa.

Lo mucho que se avanzó sobre la problemática cuando la población involucrada pertenece a los sectores populares evidencia, por oposición, lo poco que sabemos respecto al lugar que ocupan en estos procesos las clases medias. En este artículo buscamos aportar a dicha vacancia analizando un caso donde integrantes de las clases medias ${ }^{3}$ se organizaron colectivamente en la ciudad de La Plata ${ }^{4}$ (Argentina), a fin de acceder a un Programa de créditos para la vivienda, el PROCREAR. ${ }^{5}$

El PROCREAR fue una política de créditos nacional novedosa, ya que - entre otras cosas - reintrodujo el problema del acceso a la vivienda de los sectores medios a la agenda pública (Del Río, 2017). Como contraparte, una de sus líneas de crédito - Compra de Terreno y Construcción (CTC) - financió la demanda de suelo urbano sin regular su oferta, potenciando procesos de retención especulativa de suelo y subida de precios. Frente a ello, en La Plata la población beneficiaria se autoconvocó y conformó como un actor colectivo que, en tan solo un mes, logró impulsar y modelar una normativa urbana (Ordenanza 11094/13) ${ }^{6}$ que habilitó al poder ejecutivo municipal a desafectar parcelas ubicadas en zonas de uso rural intensivo y reasignarles (con destino exclusivo al PROCREAR) un nuevo indicador urbanístico denominado "zona residencial de promoción" (U/R3), el cual habilita la construcción de viviendas residenciales. ${ }^{7}$ Lograron también la incorporación en su decreto reglamentario (n. $\left.{ }^{\circ} 76 / 14\right)$ de dos modalidades específicas de implementación: la llamada Vía 2 permitió que las personas beneficiarias pudieran incidir en la localización de los barrios generados, la composición del vecindario y autogestionar los trámites y obras requeridas para su rezonificación. La Vía 3 extendió el alcance de la ordenanza a favor de quienes - al momento de su sancióneran titulares de fracciones de tierra rural indivisa bajo la figura del condominio. ${ }^{8}$ Mediante la ordenanza se generaron alrededor de 1800 lotes urbanos de los cuales 1550 nacieron de las estrategias colectivas impulsadas por las personas beneficiarias. A diferencia de aquellos municipios donde se movilizaron tierras fiscales e hicieron acuerdos de financiamiento para su urbanización, con la ordenanza 11094/13 la 
demanda de suelo se gestionó en torno a otros dos elementos. El primero, la convalidación del mercado como timonel del proceso, siendo la principal modalidad (Vía 2) un contrato entre privados donde el Estado no intervino regulando el precio del suelo. El segundo, la apertura indiscriminada del perímetro urbano, reforzando una configuración urbana extensa y difusa, con el consabido costo ambiental, social y económico que esto produce (Del Río, 2017). ${ }^{9}$

$\mathrm{El}$ artículo tiene como objetivo analizar la forma en que integrantes de las clases medias se conformaron como un actor colectivo y se inscribieron en la arena pública. Buscamos evidenciar la productividad diferencial de sus prácticas y la capacidad de generar oportunidades urbanas propias, aún en el marco de severas limitaciones estructurales. Sostendremos que su éxito para permear la estatalidad - al punto de convertirse en coproductoras de la ordenanza 11094/13 - no puede entenderse por fuera de la movilización de sus redes de contactos, saberes técnicos y expertos profesionales, del intercambio de favores, la personalización de la política y la afinidad con las burocracias estatales. Finalmente analizaremos cómo las agencias estatales respondieron a sus demandas, siendo parte central de nuestro objetivo iluminar el proceso de ciudadanización (Girola, 2017) que se dio en la intersección entre las formas asociativas de las clases medias, la producción de ciudad y la estatalidad.

El primer apartado repone el modo en que las personas beneficiarias del PROCREAR se conformaron como un actor colectivo, transformaron su demanda en un problema público y se implicaron en la redacción de la ordenanza. Vamos a sostener que la posibilidad de ser co-gestores de la normativa urbana depende de la puesta en circulación de su capital social y de la marcada presencia de profesionales en el colectivo. En el segundo, se analiza cómo - una vez lograda la sanción de la ordenanza- la efectiva urbanización y subdivisión de los predios depende en gran parte de su capacidad para circular al interior del Estado, superar obstáculos técnicos y conseguir favores burocráticos. Buscamos con ello mostrar la productividad de la acción colectiva de estos sectores en el devenir de la estatalidad y en particular, en la producción de ciudad. Finalmente, en un tercer apartado, se analiza el trabajo político realizado por las clases medias (y la moralización diferencial que recae sobre él) para lograr sus rezonificaciones y su influencia en la disputa de recursos públicos urbanos en instancias participativas.

Para llevar adelante esta investigación se adoptó un enfoque metodológico cualitativo cuya principal herramienta de producción de datos fue una etnografía virtual (Hine, 2004) donde se analizaron las interacciones generadas en dos grupos de Facebook, el Grupo Unificado PRO.CRE. AR LA PLATA Terreno + Construcción - mediante el que se organizaron las personas beneficiarias autoconvocadas- y Condominios Organizados La Plata - que nuclea a personas propietarias de terrenos en condominios-. Complementariamente realizamos observaciones de campo y 20 entrevistas en profundidad a personas beneficiarias y funcionarios y funcionarias estatales implicados en la rezonificación de los predios.

\section{Andamiaje analítico}

Hay dos discusiones conceptuales que subyacen a nuestro argumento y, por lo tanto, debemos explicitar: (a) aquella referida a la participación ciudadana en el marco de políticas públicas y (b) la dedicada a los procesos de ciudadanización que se producen en la producción participa- macroeconomía, mercado inmobiliario e industria de la construcción, donde el desarrollo urbano no se tradujo en mejores condiciones de acceso a la vivienda y al espacio urbano para amplios sectores de la población. El crecimiento local de la figura del condominio se explica también porque en La Plata, se produjo una reforma (y flexibilización) en el Código de Ordenamiento Urbano (2010) que repercutió en las expectativas de rezonificación urbana y subdivisión de quienes compraran fracciones indivisas de tierra rural bajo la figura del condominio. Frente a ello, en la periferia platense, promotores inmobiliarios y un sector minoritario de jóvenes de clases medias comenzaron a comprar fracciones rurales indivisas bajo la figura del condominio, con la expectativa de rezonificarlas primero y subdividirlas después. La extensión de la figura del condominio, entonces, tiene un doble origen en la ciudad. Algunos de ellos fueron generados y comercializados por promotores inmobiliarios, constituyéndose como una estrategia plenamente mercantil. Otros condominios surgieron del agrupamiento de personas amigas y/o conocidas a fin de comprar colectivamente fracciones indivisas de suelo rural en las periferias platenses. Aquí el rasgo distintivo, además del origen de la oferta, es la demanda, ya que las partes indivisas no eran compradas descoordinadamente por personas que no se conocían entre sí, sino por grupos previamente conformados. Fueron estos últimos tipos de condominios los que impulsaron y aplicaron a la vía 3 de la ordenanza 11094/13.

9 Para un análisis de las consecuencias socio-territoriales de la ordenanza y el lugar que en ellas ocupó la acción colectiva de las beneficiarias, ver Ventura (2020b). 
tiva de ciudad y en las interacciones entre los distintos grupos sociales y las agencias estatales.

En América Latina, la crisis de la sociedad salarial —iniciada en 1975 y profundizada en 1990 - trajo consigo una mutación en la anterior matriz estatal, caracterizada por criterios de intervención universalistas y homogeneizadores (Roffman, 2007). A su vez, y grosso modo, la complejización de la cuestión social impactó en una nueva dinámica de los sistemas políticos regionales, caracterizada por el ataque a sindicatos y partidos políticos, canales de representación tradicionales. En esa trayectoria, hacia 1990 los organismos internacionales comenzaron a promover políticas descentralizadas y focalizadas basadas en la idea de participación ciudadana, un ideal opuesto a la participación comunitaria y política de objetivos sistémicos (ob. cit). La legitimidad de este proceso arraiga, asegura Landau (2008a), en una metáfora espacial desde la cual el Estado (los políticos y las políticas) está "lejos" de la gente y por tanto no logra "escucharla". Más aún, la supuesta ineficiencia estatal descansa en este hiato, siendo la participación ciudadana una forma de "acercar" gobernantes y gobernados y con ello hacer más "saludable" el funcionamiento social y estatal.

Ahora bien, situar el problema de la representación en la lejanía entre personas gobernadas y gobernantes - y proponer a la participación como garantía del "buen gobierno"- pone el acento en las y los políticos y encubre las falencias sistémicas de las políticas neoliberales (ob. cit). El mandato de participación encubre también la capacidad diferencial que tienen los grupos para movilizar recursos, generar interacciones e incidir en las instancias de participación. Lo mismo sucede respecto a las disputas de sentido que allí se dan, las cuales implican intereses y representaciones específicas (Catenazzi y Chiara, 2007).

Sin subestimar estos recaudos, no es conveniente pensar los procesos participativos de modo lineal ya que sus potencialidades y límites dependen de variables que se actualizan y transforman en la práctica. Analizar empíricamente las instancias participativas permite, entonces, identificar a los actores más aventajados y fortalecer a los más vulnerables (ob. cit). Asimismo, cuando los procesos participativos se articulan con la producción de ciudad esto se vuelve especialmente relevante, ya que la metáfora espacial encuentra en las ciudades un espacio fértil para arraigarse, convirtiéndose estas en ámbitos privilegiados para desarrollar las categorías políticas que sustentan a los modos de gestión participativa (Landau, 2008a). De este modo, en las ciudades contemporáneas se desarrollan formas de participación a escala local que complejizan los estudios sobre la ciudadanía. Vinculado a ello, el segundo eje conceptual en el que se amojona el artículo es aquella discusión abocada a los procesos de ciudadanización que se dan en el espacio urbano (Garibotti, Girola y Boroccioni, 2017).

Fundamento del contrato político liberal, la noción de ciudadanía es entendida, desde una definición mínima, como el vínculo jurídico que une a un individuo con un Estado, convirtiéndolo en sujeto político con derechos y obligaciones universales. Tempranamente, esta concepción universalista y estática fue cuestionada por el marxismo y diversos movimientos sociales al señalar que factores como el género, el origen, las condiciones sociales de vida, etc. determinan el status de ciudadanía (Thomasz y Girola, 2015). Siguiendo este camino debemos preguntarnos cómo la localización asignada en la ciudad y la forma en que los distintos grupos se inscriben en ella, impactan en la coexistencia de distintos tipos de ciudadanías en un mismo Estado (ob. cit.). Las 
ciudades contemporáneas muestran con nitidez la forma en que distintos grupos sociales se implican en la vida pública mediante demandas reivindicativas en las que se dirime el acceso desigual a derechos y recursos de la sociedad (Ramírez Kuri, 2007). Es en ellas, por tanto, donde se construyen las significaciones en torno a pertenecer (o no) a la sociedad (ob. cit). Las formas asociativas que se dan en su interior expresan esa complejidad.

Para cerrar, la discusión de la ciudadanía no está completa sin la pregunta por el modo en que las distintas agencias estatales responden a las demandas de los grupos. Tal como muestra Auyero (2013), en sus respuestas cotidianas (y aparentemente intrascendentes) las agencias estatales ejercen una pedagogía de la dominación, performando las expectativas futuras de la población. A la inversa de lo hallado por Auyero al analizar las interacciones cotidianas de los sectores populares con las burocracias estatales, mostraremos que la rápida respuesta que recibieron en La Plata las clases medias organizadas, corrobora sus propios sentidos en torno a su lugar ocupado en el Estado y en la ciudad. En última instancia corrobora la calidad de su ciudadanía.

En lo que sigue indagaremos en los recursos movilizados y apropiados en instancias participativas vinculadas a la producción de ciudad por colectivos de clases medias, y en los procesos de ciudadanización que allí tienen lugar.

\section{Resultados y discusión}

\section{De la emergencia del actor colectivo a la co-producción de normativa urbana}

Cuando en la vida social se presenta una controversia como lo fue el subsidio de suelo urbano en un mercado desregulado - nos referimos al lanzamiento de la línea de créditos CTC del PROCREAR—, ${ }^{10}$ la naturalización de la experiencia cotidiana se agrieta. Sin embargo, ello no alcanza para que una disrupción se transforme en un problema público (Cefai, 2012), estos solo adquieren ese status si logran ser construidos como tales (Pereyra, 2017). En La Plata fueron las personas beneficiarias del PROCREAR quienes, frente a los procesos de subidas de precio del suelo urbano y la retención especulativa potenciada tras el anuncio de la línea CTC, traccionaron este proceso, tematizándolo como un problema público.

El 16 de noviembre de 2013, en una plaza céntrica, se reunieron por primera vez alrededor de 50 personas beneficiarias que tres semanas antes habían resultado ganadoras del sorteo ${ }^{11}$ que las convertía en preadjudicatarias de la línea de crédito CTC. Ese mismo día, una beneficiaria creó un grupo de Facebook para intercambiar información general, donde rápidamente el precio de los terrenos y su retención por parte de la oferta se volvieron el tema central. El acelerado crecimiento del grupo de FB motivó que pusieran fecha para su primer encuentro offline (Valadés García, 2011). Ese día nació el colectivo de personas beneficiarias y con ello un vertiginoso itinerario que terminó apenas un mes después, con la sanción de la ordenanza 11 094/13 impulsada y legitimada por el grupo que, para ese entonces, ya contaba con más de 2000 miembros. ¿Cómo fue posible que, a un mes de su primera reunión, el colectivo entablara un fluido y productivo diálogo con la $\mathrm{Mu}-$ nicipalidad logrando la sanción de una normativa urbana?
10 La modalidad CTC financió tanto la construcción de la vivienda como la compra del suelo urbano donde esta se emplazaría. Su lanzamiento, desarticulado de estrategias integrales para la generación de suelo, se constituyó en un error estratégico en el diseño del PROCREAR. 11 La posibilidad de aplicar al PROCREAR se definía mediante un sorteo público realizado mediante la Lotería Nacional. 
El primer encuentro offline fue pragmático, concentrándose en qué recursos podrían movilizar a fin de acceder a suelo urbano. En ese marco y en una suerte de socialización de sus capitales sociales y culturales (Bourdieu, 1985) alguien dijo conocer a la secretaria privada del intendente, otra persona agregó que tenía vínculo con un senador y una trabajadora de la Subsecretaría Social de Tierras, Urbanismo y Vivienda de la provincia de Buenos Aires se ofreció "a hacer llegar" a las autoridades de esa dependencia el documento generado. Allí se evidenció que quienes estaban allí eran poseedores de ciertos conocimientos y redes sociales que serían claves para el futuro de la organización y la disputa por hacer valer sus demandas.

La movilización de redes personales para acceder a la agenda gubernamental operó en parte como una lógica implícita e incorporada, una "manera de hacer" (De Certeau, 1999) que les resultaba familiar. Fue también una estrategia colectiva manifiesta. Tal es así que no consideraron recurrir a repertorios tradicionales de acción colectiva argentina - como los cortes de calle o la difusión en la vía pública de su problemática-; en su lugar, evaluaron que la movilización de contactos personales en el menor tiempo posible era el mejor recurso para inscribir su demanda como un problema público. El consenso fue total. La inmediata puesta en circulación de su capital social, mostró ser eficaz al punto tal que un día después consiguieron el compromiso del intendente - Pablo Bruera- de darles cita a la brevedad. Ahora bien, un problema público se configura en una simultaneidad de escenas, más o menos institucionalizadas (Cefai, 2012). Sin ser su prioridad, ni su mayor apuesta, las personas beneficiarias se inscribieron también en la escena mediática de la ciudad. También en este punto se encontraron en una situación aventajada asociada a sus redes de relaciones personales y los recursos que podían movilizar con ellas. Estas redes estaban además jerarquizadas, conteniendo personas funcionarias, políticas y técnicas estatales y colegas. El modo en que las pusieron en circulación y a disposición de las demás, también fue relevante ya que desde el primer momento estuvieron disponibles para ser activadas y colectivizadas. ${ }^{12}$

Ahora bien, esto no agota ni explica la capacidad de las clases medias para - una vez inscriptas en la arena pública- convertirse en coproductoras de la ordenanza, logrando además imponer en su decreto reglamentario la incorporación de las llamadas Vía 2 y Vía 3. Para ello fueron centrales otros dos aspectos: que el colectivo se comporte como una comunidad de profesionales y que se articule con naturalidad a los espacios de decisión pública.

Respecto al primer punto, la presencia de profesionales y personas trabajadoras estatales en el colectivo posibilitó traducir casi naturalmente sus demandas a dispositivos técnicos y lógicas burocráticas, permitiéndoles dialogar fluidamente con las técnicas y los técnicos estatales e intervenir en las modalidades habilitadas por la ordenanza. El trabajo de traducción, dice Latour (1998), es siempre una instancia de producción de sentido que puede implicar ganancias o pérdidas. A diferencia de otros grupos sociales, que para emplazar su problemática en el ámbito del derecho necesitan de especialistas (Melé, 2016), en el caso que presentamos fueron las propias personas protagonistas quienes juridificaron (Azuela, 2006) el conflicto asegurándose de no tener "pérdidas de traducción". Las personas beneficiarias del PROCREAR contaron con ventajosas capacidades de (auto)gestión ya que, al fin y al cabo, se trataba de una comunidad de profesionales.

12 En futuros trabajos, siguiendo a Barozet (2006), analizaremos el lugar de las redes sociales como elemento estructurarte de la posición ocupada en el espacio social y urbano. 
Lo anterior permitió un diálogo directo con el municipio en torno al contenido de la normativa, y ser su propia asistencia técnica tuvo un efecto en la re-categorización jurídica del espacio urbano. Asimismo, la acción mediadora y generalizadora del conocimiento experto y del uso de dispositivos técnicos (registro escrito, certificaciones institucionales, formularios, notas, etc.) permitió también burocratizar sus prácticas (Perelmiter, 2016) agilizando el vínculo con el gobierno municipal. Finalmente, además de permitirles participar en la redacción y reglamentación de la norma, el conocimiento jurídico guió decisiones, favoreció las negociaciones con las personas propietariras de suelo y con diferentes actores de la industria de la construcción. Lo mismo sucedió con quienes tenían otras profesiones afines a la problemática: personas arquitectas, ingenieras, contadoras, agrimensoras, comunicadoras, etc. estuvieron activas y disponibles para el colectivo, facilitando y abaratando todo el proceso.

\section{Nativas del laberinto: las clases medias y su circulación al interior de la estatalidad}

Hasta acá intentamos poner de relieve la forma en que las personas del PROCREAR se conformaron como actor colectivo, vehiculizaron sus demandas y se implicaron en la redacción de una normativa urbana colectivizando - en base a la afinidad de clase- sus capitales social y cultural. A lo largo del trabajo de campo encontramos también que la efectividad de las clases medias radicó en que hablaron la misma lengua de la estatalidad.

Ello se vio especialmente en la implementación de la llamada Vía 3 de la ordenanza, para la cual se estableció (Decreto reglamentario $\mathrm{N}^{\circ}$ 76/14) un procedimiento de rezonificación más riguroso que el previsto para la Vía 2 (Vértiz, 2016). Requería, por ejemplo, una ordenanza individual sancionada por el Concejo Deliberante a fin de otorgar la rezonificación de cada condominio. Ello implicó un arduo trabajo político, burocrático y técnico por parte de las personas propietarias de condominios -organizadas en un sub-colectivo denominado $\mathrm{La} \mathrm{COLP}^{13}$ (Ventura, 2020a) - a fin de que todos pudieran presentar conjuntamente la documentación requerida y no perder fuerza de negociación colectiva.

Nuevamente, al momento de generar y presentar dicha documentación, fue nodal la composición social de la COLP - la mayoría profesionales y/o trabajadoras y trabajadores estatales de entre 30 y 40 años- Algunas desempeñaban funciones en áreas estatales involucradas en las rezonificaciones de los predios, lo que permitió contar con asesoramiento técnico personalizado para la realización de los trámites requeridos. Disponían también de redes de contactos que eventualmente podían hacerles favores burocráticos. Lo mismo sucedió en la Vía 2. Allí, además del asesoramiento técnico, "pertenecer" a áreas estatales específicas les permitió acelerar trámites mediante el intercambio de favores dentro de la comunidad de beneficiarias:

Imaginate que en Autoridad del Agua hay gente de alguno de los loteos de la ordenanza, en Catastro hay gente de alguno de los loteos, en el Instituto de la Vivienda hay gente de alguno de los loteos, entonces si llegaba de un loteo un formulario de pedido de la factibilidad hidráulica, había uno que decía "che, este es de los chicos de tal lado, ¿no me hacés la gauchada?, ¿me lo hacés correr más rápido?”. Y bueno, hemos agilizado mu-
13 Red de Condominios Organizados La Plata. Excede a los objetivos de este artículo profundizar en las particularidades de este sub-colectivo. 
chos trámites simplemente por estar en el lugar donde la gente tenía que estar. [Entrevista a Gael, integrante del colectivo de personas beneficiarias del PROCREAR].

Tal como afirma Perelmiter (2007), la frontera entre lo que llamamos Estado y la sociedad es borrosa. En el caso analizado, además, fue cruzada cotidianamente por las clases medias organizadas. Independientemente de su llegada a áreas específicamente vinculadas a la problemática, las personas beneficiarias contaban con un conocimiento cotidiano del habitus estatal. Tal como afirma Christian:

Además de tener la voluntad, nosotros conocemos los laberintos del Estado: sabemos por dónde tenemos que ir, cómo tenemos que movernos, dónde están los expedientes, etc. Por ahí, si hubiésemos sido gente que no está en la burocracia, hubiéramos pasado de largo (Entrevista a Christian, integrante de la COLP).

A ello se suma que el proceso de implementación de la ordenanza fue pensado por las personas beneficiarias como una co-gestión simétrica entre las partes. Esta pretendida simetría caracterizó tanto su relación con los cuadros políticos como con los técnicos del municipio. En ambos casos, sin importar la jerarquía de las personas funcionarias, los encuentros no se planteaban como espacios de consulta o reclamo sino como instancias de "trabajo conjunto".

Asimismo, la COLP contó con la predisposición de personas trabajadoras de distintas áreas que desde el primer momento ofrecieron asesoramiento y agilizaron los trámites municipales. En una ocasión, por ejemplo, un expediente presentado por la COLP se extravió al interior de una oficina. ${ }^{14}$ Frente a ello, una beneficiaria ofreció dedicar su mañana a "buscar los expedientes personalmente", argumentando que, si el personal municipal no había podido hacerlo hasta ahora, ella podía encargarse. Buscar "los expedientes personalmente" formaba parte de su mundo posible, encontrando natural ingresar a una dependencia estatal y, sin ser supervisada, acceder a información sensible examinando una a una las carpetas de la oficina. Esta escena muestra, por un lado, la naturalidad con que circularon al interior del Estado (incluso donde no tenían personas conocidas o fueran ellas mismas las personas trabajadoras) y, por otro, la auto-jerarquización de sus prácticas, dos rasgos que signaron todo el proceso. Dicho de otro modo, sus interacciones con la estatalidad estuvieron regidas por determinadas expectativas en torno a qué podían y qué no podían pedir al Estado, y cuáles eran las respuestas esperables conforme a su lugar en la estructura social.

Así sucedió al momento de realizar un Proyecto Hidráulico, requisito técnico para poder aplicar a la ordenanza 11094/13 y generar un futuro barrio. Para la realización de dichos Proyectos, el municipio designó un número acotado de ingenieros e ingenieras-externos al municipio-, quienes eran las únicas personas habilitadas para hacerlos. Las personas beneficiarias, sin embargo, lograron revertir esta decisión desde la convicción de que el grupo de profesionales que ellas podían aportar eran mejores que los propuestos por el municipio:

14 A fin de resguardar la identidad de las personas trabajadoras no especificaremos las áreas estatales involucradas.
Fuimos con el director de la Universidad Tecnológica Nacional, entonces no lo podían cuestionar, porque los suyos eran unos cuatro de copas y nosotros fuimos con el mejor (Entrevista a Luna, integrante de la COLP). 
Esta auto-percepción también rigió su relación con otros actores. Inés, por ejemplo, tuvo dificultades con la escrituración de su lote:

Los escribanos se manejan como si fueran semi-dioses, el peor es Benavidez $[\ldots]$ el tipo me dice "no, porque yo soy el presidente del Colegio de Abogados”. Le respondí: ¡Mirá vos, y yo soy Inés Montoya Burgos, ¿a mí qué me importa quién seas?" (Entrevista a Inés, integrante de la COLP).

En otra ocasión, al entablar negociaciones por un predio a rezonificarse mediante la Vía 2, Gael se sintió intimidado por un importante agente inmobiliario local:

Yo estuve en una reunión con García y el tipo me presumió todas sus titularizaciones de campos y todas las cosas en las que había invertido y yo pensaba "bueno García, está bien. Yo fui a la Universidad, no sé si será lo mismo" (risas) (Entrevista a Gael, integrante del colectivo de personas beneficiarias del PROCREAR).

En estos relatos se deja ver cómo las clases medias organizadas no validaron criterios de jerarquización social basados en el capital económico o los altos cargos; al contrario, jerarquizaron sus redes sociales, sus credenciales educativas y su relativa autonomía de las autoridades. En su circulación al interior del Estado, dicha auto-jerarquización partía de la convicción de que sus aspiraciones y derechos ameritaban una rápida respuesta de las burocracias y los cargos políticos. Percepción que no surgía únicamente de sus imaginarios; su experiencia frente al Estado validaba la premisa: durante todo el proceso personas funcionarias y empleadas estatales trabajaron fuera de horario, fungieron de nexo con otras áreas, corrigieron documentación informalmente, etc.

Lo anterior evidencia cómo las burocracias, lejos de ser impersonales y procedimentales, son selectivas, introduciendo sus agentes diferencias de clase, tanto en el modo en que interpretan necesidades como en las respuestas que dan a ellas (Perelmiter, 2016). Al respecto, Auyero (2016) sostiene que, en sus respuestas cotidianas, las agencias estatales ejercen una pedagogía de la dominación. Cuando las personas pobres interactúan con las burocracias, estas les dan lecciones políticas y performan las expectativas futuras en tanto ciudadanía. Así, en interacciones aparentemente intrascendentes, las agencias del Estado "imparten educación política, cursos intensivos diarios acerca del funcionamiento del poder a los sectores pobres" (Auyero, 2016, p. 22). De este modo, las condiciones impuestas para la realización de distintos trámites o solicitudes desalientan o promueven las demandas al Estado y ayudan a determinar "las percepciones de los beneficiarios en cuanto a su propio estatus y autoridad en relación con las instituciones y al personal estatal" (Auyero, 2016, p. 23). A la inversa de lo hallado por Auyero, encontramos que la rápida respuesta que recibieron en La Plata este grupo de jóvenes profesionales validó su propio sentido en torno al lugar ocupado en el Estado. Aún más, las respuestas favorables por parte de las distintas agencias no fueron leídas como producto de la voluntad política de una gestión particular sino como una consecuencia evidente de sus cualidades, méritos y posición social.

En síntesis, el proceso por el cual las personas beneficiarias superaron colectivamente y con éxito los obstáculos técnicos-burocráticos para acceder a suelo urbano, informa tanto de sus propios recursos como del funcionamiento cotidiano de la estatalidad. La realidad em- 
pírica de la vida estatal se caracteriza por una multiplicidad de actores que tienen acceso a ella e intervienen en su proceso de formación. En cada contexto, entonces, hay que ver qué actores y mediante qué prácticas logran incidir en las dinámicas de las distintas áreas estatales (Perelmiter, 2007). El caso estudiado informa de la productividad que tienen las clases medias en el devenir de la estatalidad y permite comprender cómo en la producción de ciudad, la selectividad que permea al Estado tiene una dimensión cotidiana y discreta.

\section{El trabajo político de las clases medias en sus disputas por la producción de ciudad}

Dijimos antes que la rezonificación de los condominios (Vía 3) requería una ordenanza individual sancionada por el Concejo Deliberante. En este punto, la COLP ya no debía presionar al poder ejecutivo local sino al legislativo. En esta nueva arena (la legislativa) la comodidad con que habían circulado por la estatalidad quedó atrás, ya que su trabajo técnico-burocrático encontró un límite y se relativizó la efectividad de la movilización de vínculos personales, debido a que las decisiones que pudiera tomar cada uno de los bloques legislativos dependía mayormente de las negociaciones propias del juego político (Perelmiter, 2012) de las relaciones interbloque.

Para este trabajo de "convencimiento", la COLP configuró un listado de cada uno de los concejales y concejalas allegados a las distintas fuerzas políticas y comenzó a recorrer diariamente los pasillos y despachos del municipio interpelándolas. Las prácticas y la disposición subjetiva de este grupo de jóvenes de clases medias, puestos en situación y conocedores de los laberintos estatales, se manifestaban como atípicas en el ambiente municipal. Maximizar el efecto de la sorpresa y la insistencia, fue parte de la estrategia de la COLP.

El ingreso del colectivo al juego político implicó además la latencia de un conflicto, ya que las incorporaciones de las Vías 2 y 3 no siguieron la misma lógica: mientras que la Vía 2 fue producto de negociaciones del colectivo de personas beneficiarias auto-convocadas, la incorporación de la Vía 3 fue sorpresiva e irrumpió en la escena producto de la contingencia política. En concreto, dos días antes de que se sancione la ordenanza, un funcionario municipal de baja jerarquía - Camiloconvocó a las personas propietarias de distintos condominios a una reunión informal donde les propuso conformar un sub-colectivo - la COLP-y pujar por la incorporación de una modalidad que permitiera regularizar la situación de sus predios para acceder al PROCREAR. En este sentido, la incorporación de la Vía 3 se definió por negociaciones entre Camilo y los principales representantes del poder ejecutivo local. Fue así que, cuando la COLP decidió ingresar al juego político interbloque, la mediación de aquel funcionario fue tensionada y excedida. Si bien Camilo desalentó las reuniones entre la COLP y otros referentes políticos — quienes en algún punto podían disputar la capitalización de sus gestiones- la COLP no dio lugar a cuestionamientos concretando sus encuentros. Esta tensión, sin embargo, no se tradujo en un conflicto manifiesto con el bruerismo. ${ }^{15}$ Más aún, lejos de cortar el vínculo, la COLP intensificó sus demandas:

15 Refiere a la fuerza política encabezada por Pablo Bruera, en ese entonces intendente de la ciudad. Camilo formaba parte de aquella gestión.
"Pregunta: ¿alguien le avisó a Camilo que necesitamos que la reunión de la semana próxima sea con el abogado del municipio?”; "Camilo, nos podrás armar una reunión cuanto antes con el secretario de Planeamien- 
to? [...] necesitamos que ya empiecen a bajar los expedientes completos al Concejo Deliberante"; "hay que reunirse lo antes posible. Puede ser mañana martes? Camilo se puede en el parque? Podés averiguar qué pasa con los Concejales Nac \& Pop? Si nos van a apoyar?”; "Camilo: queremos saber si nos podes decir si el martes que viene se hace la reunión de la comisión de Planeamiento [...]. Le podés pedir al intendente que nos deje participar?", etc. (Las citas corresponden a publicaciones realizadas en el muro de facebook de la COLP a lo largo de todo el proceso).

Además de exigir productividad, la COLP daba por hecho que Camilo debía realizar las gestiones necesarias ante sus demandas. Ahora bien, a pesar de que este dio respuestas durante todo el proceso, no logró como contrapartida obtener un gesto de acompañamiento político de la COLP. En este sentido, si bien se entabló una relación política personalizada mediante la cual la COLP obtuvo la rezonificación de sus predios y, como contra don, se les solicitaron gestos de acompañamiento político, estos no se dieron.

Si bien las discusiones sobre relaciones políticas personalizadas nos exceden, queremos aportar algunas reflexiones al respecto. En América Latina, clientelismo político es a la vez la categoría analítica por excelencia para referir a una relación política personalizada en la que intervienen formas de reciprocidad e intercambio (Vommaro y Combes, 2016) y una etiqueta moral para denunciar fallas respecto a los ideales políticos liberales. Estas formas de descalificación recaen en parte en los partidos políticos y en parte en los sectores populares, en apariencia los únicos que forman parte de relaciones políticas personalizadas. También analíticamente las miradas se centran en dicho sector, siendo pocos los trabajos que utilizan esta categoría para tipificar y comprender prácticas comparables en otros estratos sociales (Kessler, 2016).

En la implementación local del PROCREAR —al igual que en las redes clientelares estudiadas en los barrios pobres- la personalización de la política fue un proceso transversal que se dio con matices. En el caso del colectivo auto-convocado que dio origen a la ordenanza, la personalización de la política no dependió de agentes mediadores externos - aquella figura que opera distribuyendo recursos y protección (Auyero y Benzecry, 2016) - sino que la realizaron ellas mismas mediante sus amplias redes de contactos y de una relación simétrica con la estatalidad. Tal como afirma Barozet (2006) las clases medias se involucran en el intercambio de favores con la estatalidad, pero no lo hacen regidos por la desigualdad de poder entre quien hace el favor y quien lo pide. En cambio, consiguen bienes y servicios mediante el intercambio horizontal de favores, entre iguales. Ese fue el caso de las personas beneficiarias autoconvocadas: no se trató de una "amistad desnivelada" (Auyero y Benzecry, 2016) sino de relaciones habitualmente simétricas y productivas con el Estado.

En el caso de la COLP sí hubo un mediador externo - Camiloque, sin embargo, no logró el acompañamiento político de la organización. Es sugerente pensar las razones de este desencuentro. Por un lado, como venimos argumentando las clases medias lograron moverse eficientemente al interior del Estado por sus propios medios. Transitar con naturalidad el acceso a la vida estatal y obtener respuestas positivas, pudo haber dificultado a dicho funcionario la operación de atribuirse el mérito por las gestiones realizadas. A su vez, las dificultades para capitalizar sus gestiones pueden vincularse a que la COLP fue indiferente a las condiciones tácitas de intercambio propuestas por Camilo. 
16 En el año 1989, en Porto Alegre (Brasil), el Partido de los Trabajadores lanzó una política pública conocida como "Presupuesto Participativo”, la cual se expandió primero a otros municipios de Brasil, y luego al resto de América Latina (Carmona y Martínez, 2013). En Argentina el PP — política de alcance municipal— inició su trayectoria en el año 2001, implementándose en los municipios de Capital Federal, Godoy Cruz (Provincia de Mendoza) y Rosario (Provincia de Santa Fe); en estos últimos dos distritos de modo ininterrumpido desde principio de los años 2000 hasta el año 2018 (Martínez, 2018). A partir de dichas experiencias, el PP comenzó a implementarse en otras jurisdicciones nacionales generándose la "Red Argentina de Presupuesto Participativo", en la cual se nuclearon los distintos gobiernos locales que aplicaron esta política (Martinez, 2018),. Hacia el año 2011, el PP se había implementado en al menos 35 municipios Argentinos (Martínez y Arena, 2013), trazando cada una de las gestiones locales, diseños institucionales propios para su implementación (Ramella, 2012).

17 En La Plata, la metodología del PP consistió en la división de la ciudad en 35 zonas. En cada una de ellas se previó la realización de 4 asambleas barriales donde el vecindario -individualmente o mediante organizaciones sociales-podía presentar proyectos de competencia municipal -equipamiento de espacios comunitarios como plazas o parques; mejorados de calles; iluminación; etc.- - Una vez presentados, el municipio sometía dichos proyectos a una evaluación técnica y financiera a su cargo. Luego — en la cuarta asamblea- los proyectos que pasaban dicha evaluación, eran sometidos a votación vecinal; el que recibía mayor cantidad de votos se implementaba. Para el PP el gobierno municipal asignó un $2 \%$ del Presupuesto General del municipio de La Plata (Pagani y Arce, 2008).
Tal como afirman Vommaro y Combes (2016), conviene analizar las relaciones de intercambio político personalizadas desde la noción de "economía moral" (Thompson, 2012). Desde esta perspectiva, las relaciones entre actores políticos se organizan moralmente y se fundan en nociones compartidas de justicia. Los actores deben ser parte de una misma configuración normativa que defina los "derechos", "méritos" y "obligaciones" que regulan el acceso a los recursos estatales. La fisura en la reciprocidad del vínculo entre la COLP y el mediador, responde en parte a que los actores no se rigieron con la misma configuración moral: para la COLP obtener facilidades estatales mediante favores personales apareció como un proceso justo y natural, pero no que se les solicite como contra don el acompañamiento político.

Nos detenemos en este punto porque en nuestro trabajo de campo encontramos que las configuraciones morales respecto a la vida política, además de guiar las prácticas de las personas beneficiarias, penetran $-\mathrm{y}$ constituyen - la estatalidad, repercutiendo en la apropiación y gestión de recursos públicos. Así sucedió en dos instancias en las que las clases medias organizadas en torno al PROCREAR se implicaron en la implementación del Programa de Presupuesto Participativo (PP). Como mencionamos al inicio, la participación ciudadana es en parte un meta-relato asociado a la garantía del "buen gobierno". En Argentina, una política de promoción de la participación implementada fue el $\mathrm{PP}^{16}$ (Pagani y Arce, 2008) que a nivel local consistió en instancias asamblearias institucionalizadas donde la población determinaba cuáles eran las prioridades barriales en las que destinar recursos municipales. ${ }^{17}$

En una de estas asambleas, integrantes de la COLP presentaron el proyecto de abrir una calle que llegara hasta sus condominios. Los condominios en cuestión —equivalentes a 64 hectáreas- se localizan en Arana, un barrio rural tradicionalmente habitado por trabajadores del sector fruti-hortícola. El barrio lindero, Parque Sicardi, experimentó en las últimas décadas un fuerte cambio en su morfología, pasando del predominio de casas de fin de semana a la conformación de viviendas permanentes, lo cual se tradujo en un crecimiento poblacional exponencial. Ambas delegaciones compartieron asamblea por el PP, generándose un conflicto cuando el proyecto presentado por integrantes de la COLP — quienes aun no habitaban en Arana - ganó la partida presupuestaria asignada:

Competíamos contra proyectos de Sicardi donde viven 11 mil personas y lo que pedíamos nosotros era algo estrambótico: pedíamos asfalto para poder ingresar a los terrenos y claro cuando fuimos a las asambleas decían "estos están re locos”. Porque nosotros ¿qué hicimos? Planteamos una estrategia para que ellos no se dieran cuenta que en realidad éramos muchos más de lo que aparentamos [...] es decir, vos vas al condominio y es campo y entonces los de Sicardi decían "es campo, no les van a dar asfalto, son 3 delirantes!" Pero claro, lo que hicimos fue mandar 2 personas a las asambleas, el proyecto ingresó, no nos dieron bola y cuando fuimos a votar le llevamos 700 personas y ellos fueron 300 (Entrevista a Christian, integrante de la COLP).

Al preguntarle a Christian si esto generó conflicto entre los condominios y el barrio lindero, continuó:

Si!! En realidad el conflicto lo tienen ellos porque de 11 mil personas solo votaron 300. Nosotros no queremos que el pobre se coma al pobre, 
pero bueno, lo nuestro partió de la organización, hicimos un plan sistemático y lo llevamos adelante. Se hicieron padrones para ver cuánta gente tenía que llevar cada uno a votar, hicimos una proyección como si fuese una elección. O sea, hay organización porque hay mucha gente que está convencida de que se quiere ir a vivir ahí (Entrevista a Christian, integrante de la COLP).

La segunda asamblea del PP a la que nos referimos corresponde a la zona norte de la ciudad. Allí las personas integrantes de un loteo generado mediante la Vía 2 presentaron un proyecto, también para el mejoramiento de calles. En esta ocasión perdieron frente al barrio lindero, habitado por sectores populares. A pesar de ello el municipio se comprometió a realizar las obras contempladas en su proyecto. Dice Carla al respecto:

En el PP salimos segundos, no ganamos, pero en los votos sumamos como 350 personas mientras que el hermano del intendente venía con los camiones llenos de gente que traía a votar [...] los hacían votar de acá para allá, en todos lados. Así que al final desde el municipio nos dijeron que nos van a hacer las calles a nosotros, porque perdimos en los números, pero solo porque ellos inventaron gente a la que hicieron votar donde ellos quisieron. Nos las van a hacer porque vieron que movimos 350 personas, que para ese barrio es una bestialidad. Así que estamos esperando las calles porque somos un grupo que nos hacemos ver (Entrevista a Carla, beneficiaria del PROCREAR).

Estas escenas iluminan la moralización diferencial que recae sobre relaciones políticas personalizadas conforme a si las protagonizan sectores medios o bajos. A lo largo del artículo mostramos cómo el acceso a recursos públicos mediante relaciones personales y la lógica del intercambio, fueron nodales en las prácticas de estos colectivos y tuvieron efectos en la recategorizacion (y posterior ocupación) del espacio urbano. Sin embargo, en las narrativas de las beneficiarias y la COLP estos vínculos no fueron leídos como personalización de la política y, si lo fueron, no recayó sobre ellos una moralidad des-legitimante. Distinta es la disposición subjetiva al analizar los vínculos políticos personalizados e informales entre la estatalidad y los sectores populares. Así, por ejemplo, para Carla es autoevidente que a pesar de que su proyecto haya perdido en la asamblea del PP, el municipio debía realizar las obras. Esto es así porque los votos del proyecto ganador no eran legítimos: habían sido "llevados" (en camiones) a votar "de acá para allá". Se opone de este modo una inscripción en los procesos participativos que es pasiva y dependiente de la vida política local - la de los sectores populares - a otra protagonizada por ellos mismos - las clases medias - que es activa, autónoma y por lo tanto más legítima. En palabras de Christian, sus cálculos respecto a "cuánta gente tenía que llevar cada uno" a votar, eran parte de las estrategias de quienes están "convencidos de que quieren ir a vivir ahí" y se organizan para lograrlo.

En segundo lugar, estas escenas iluminan un rasgo ineludible de las instancias de participación ciudadana: al mismo tiempo que tienen potencial para democratizar la vida pública, ponen en juego la distribución de recursos públicos generándose conflictos a regular. En nuestro caso, vimos cómo colectivos de clases medias cuentan con ventajas propias de su composición social _ jerarquizadas redes de capital social, colectivización de capital cultural, facilidad para transitar en las buro- 
cracias, etc.- que facilitan su inscripción en instancias participativas. Cuentan también con narrativas ventajosas para su inscripción en la gramática pública (Cefai, 2012). Una de ellas es la doctrina moral del justo medio que subyace a la metáfora espacial sobre la sociedad. Desde esta narrativa, en la vida social hay un "lugar intermedio" que representa al "locus de la moderación y la virtud" (Adamovsky, 2013, p. 47), una guía de racionalidad; en ese sentido nombrarse de clase media "es también colocarse en el (justo) medio y reclamar una ubicación en el mapa de la "civilización", una operación del orden de lo simbólico con profundas consecuencias en el plano de las relaciones entre clases" (Adamovsky, 2013, p.48). La segunda narrativa que opera, es la estrategia de la ciudadanía (Landau, 2008a) la cual promueve ciudadanos "activos" - generándose una individualización del riesgo- que no tienen como referencia al Estado - replegado frente a la seguridad socialsino a "su comunidad" (ob. cit.). En base a ella se promueve la participación ciudadana en oposición a formas de implicación "política”, erigiéndose la figura del ciudadano/a, vecino/a como una categoría que al mismo tiempo que convoca a la participación, oculta las disputas y desigualdades urbanas que se dan en ella (Girola, 2017). ${ }^{18}$ Sostenemos en este punto que - junto a las características propias de la población involucrada- la afinidad entre la metáfora del justo medio, la estrategia de la ciudadanización y la deslegitimación selectiva de las relaciones políticas personalizadas, influyen en la apropiación diferencial de recursos públicos durante la producción de ciudad.

\section{Conclusiones}

La ciudad latinoamericana es una estructura resultado de actores con desiguales capacidades de incidir en su estructuración, y un lugar privilegiado para analizar la forma en que los grupos sociales se implican en la vida pública. Es, además, epicentro de procesos de construcción de ciudadanía, una muestra privilegiada del acceso — diferenciado y desigual- a derechos y recursos de la sociedad (Ramírez Kuri, 2007). Partiendo de ahí, a lo largo del artículo nos sumamos a una pregunta clásica de los estudios urbanos latinoamericanos: cuál es el lugar de las formas asociativas de la sociedad civil en la implementación de políticas públicas habitacionales y, mediante ellas, en la producción de ciudad. Lo hicimos aportando un caso protagonizado por las clases medias. En él la participación ciudadana —en oposición a la participación políticay los procesos de ciudadanización con epicentro en el espacio urbano, fueron procesos que se entrelazaron entre sí y a formas morales específicas. Entrelazamientos que, a su vez, repercutieron en la apropiación diferencial de recursos públicos y en la forma que adoptó la implementación de una política pública de escala como fue el PROCREAR.

En primer término, encontramos que las clases medias organizadas tuvieron una posición aventajada a la hora de articularse a la estatalidad y a procesos participativos, siendo particularmente productivas al inscribirse en los espacios de decisión que les permitieron ser co-gestoras de una normativa urbana. Ello dependió en parte de la colectivización — sobre la base de la afinidad de clase- de sus capitales social (amplio y jerarquizado) y cultural (en particular la fuerte presencia de profesionales). Asimismo, una vez lograda la sanción de la ordenanza, su efectividad para lograr la urbanización y subdivisión de los predios —es decir la implementación de la normativa por ellos impulsada-

18 Ello no implica para Girola (2017) sostener acríticamente aquella idea de que los procesos de movilización vecinal se reducen a una forma de despolitización de la figura del ciudadano. 
radicó en que hablaron la misma lengua de la estatalidad. Esta familiaridad se nutrió de la presencia dentro del colectivo de personas beneficiarias de trabajadoras estatales, algunas de ellas inscritas en áreas vinculadas al proceso estudiado. La posición aventajada de las beneficiarias al momento de inscribirse en la estatalidad — superando obstáculos técnicos y burocráticos- se debió también al intercambio de favores "de igual a igual" que tuvieron con personas trabajadoras y técnicas estatales externos al colectivo. La movilización de relaciones personalizadas a fin de conseguir bienes y servicios públicos, asumió en el caso estudiado dos formas; por un lado, como ya dijimos, parte de las personas beneficiarias logró hacerlo sin necesidad de personas intermediarias externas al colectivo y mediante el intercambio horizontal de favores. Por otro lado, la COLP debió recurrir a la figura de un mediador externo; en este caso se dio un quiebre en la relación de reciprocidad tácita del intercambio político: las clases medias organizadas y el mediador político no se rigieron con la misma configuración moral. Más específicamente, para la COLP resultaba justo y autoevidente obtener facilidades estatales mediante favores personales, pero no que se les solicite como contra don el acompañamiento político.

De este modo, al trabajar sobre el trabajo político realizado por las clases medias a fin de inscribirse en la producción de ciudad, encontramos que sus interacciones con la estatalidad y con la vida política estuvieron regidas por determinadas expectativas en torno a qué podían y qué no podían pedir al Estado, y cuáles eran las respuestas esperables conforme a su lugar en la estructura social. Así, las prácticas de las personas beneficiarias platenses del PROCREAR se nutrieron de una auto-jerarquización - frente a otros sectores sociales y autoridades estatales-que no radicó en criterios como el capital económico o las posiciones jerárquicas, sino en sus propias redes sociales, sus credenciales educativas y su relativa autonomía de las autoridades. Esta auto-jerarquización partió además de la convicción de que sus aspiraciones y derechos ameritaban una rápida respuesta de las burocracias y los cargos políticos. Lo relevante del caso es que las respuestas estatales corroboraron dichas percepciones. La posición aventajada de las clases medias para inscribirse en la estatalidad, entonces, no solo respondió a los recursos propios del sector, sino también a la predisposición y celeridad de las burocracias estatales para dar respuestas a sus demandas.

En este punto, las configuraciones morales que guiaron las prácticas de las clases medias y las respuestas estatales frente a ellas, nos llevaron a pensar el proceso de ciudadanización —entendido como el acceso o exclusión a derechos- que se dio en las interacciones entre las clases medias y las agencias estatales al producir y consumir la ciudad. Nos preguntamos además cómo esto se puso en juego en los procesos de participación institucionalizados, en particular en el Presupuesto Participativo. Respecto a ello encontramos nuevamente que la articulación de las clases medias a estas instancias estuvo marcada tanto por sus propios recursos, como por narrativas que los aventajan en su paso por la gramática pública. En concreto, sostenemos que hubo una confluencia entre el mandato de participación ciudadana, la metáfora moral del justo medio y la moralización diferencial de los vínculos políticos personalizados. En estos procesos de ciudadanización, las clases medias reconfirman su lugar privilegiado en el espacio social por sobre otros grupos, al mismo tiempo en que se reproduce una separación entre ciudadanías activas y autónomas (clases medias) y ciudadanías dependientes protagonizadas por clientes pasivos (sectores populares). 
Hasta acá, entonces, la primera parte de nuestras conclusiones: las clases medias tuvieron una doble ventaja al inscribirse en las arenas estatales y en los procesos de participación ciudadana: por un lado, aquellas vinculadas a sus propios recursos y por otro las que nacieron de las configuraciones morales que guiaron tanto sus prácticas como las de las personas funcionarias y técnicas estatales. La segunda parte de nuestra reflexión es que estas predisposiciones y recursos repercutieron en la apropiación de recursos públicos, la producción de ciudad y la implementación de una política pública de escala.

Dijimos al iniciar el artículo que el PROCREAR fue una política innovadora que incurrió en un error estratégico: el subsidio del suelo urbano sin regular su oferta. Para cerrar nuestra reflexión agregamos que ante el error de diseño que significó el lanzamiento de la línea CTC, desde el PROCREAR se tomó la decisión de crear una Dirección de Desarrollo de Suelo Urbano (DDSU) destinada a planificar estrategias integrales para la generación de suelo. Una novedad interesante, dada la ausencia en la historia argentina reciente de áreas estatales nacionales que asuman el rol de desarrolladores urbanos con especial énfasis en la generación de suelo urbano. Sin embargo, antes que la DDSU pudieran estructurar alguna respuesta a la problemática del suelo, en La Plata ya se habían avanzado - con gran celeridad- en la ordenanza 11094/13. Mediante ella la demanda de suelo urbano se gestionó con criterios opuestos a los objetivos de la DDSU: se legitimó al mercado como regente del proceso, limitándose el Estado municipal a un rol de facilitador; se produjo una apertura indiscriminada del perímetro urbano, reforzando una configuración urbana extensa y difusa; y se reprodujeron procesos de segmentación social y territorial. Como argumentamos a lo largo del artículo, las prácticas y moralidades que guiaron las interacciones entre las personas beneficiarias y la estatalidad fueron nodales para dar forma a este proceso. De este modo, las personas beneficiarias reprodujeron aquellas tendencias de la ciudad capitalista que las expulsaron del mercado de suelo formal primero y las impulsaron a organizarse colectivamente después.

Bajo la luz del caso, sostenemos por un lado la importancia de analizar los procesos de implementación de políticas habitacionales siguiendo a la población beneficiaria en sus interacciones micro-situadas con la estatalidad y la productividad de sus prácticas. Por el otro, la necesidad de seguir sumando estudios empíricos críticos de los procesos de participación vinculados a la implementación de políticas habitacionales. Ello no implica negar que los procesos participativos sean potenciales espacios redistributivos que, a su vez, permitan agregar valor a las políticas públicas; por el contrario, analizar empíricamente estas instancias contribuye a dichos objetivos al permitir identificar las capacidades diferenciales que tienen los grupos sociales para movilizar y apropiarse de recursos públicos. 


\section{Referencias bibliográficas}

Adamovsky, Ezequiel. (2013). "Clase media": reflexiones sobre los (malos) usos académicos de una categoría. Revista Nueva Sociedad, 247, 38-49. Recuperado el 5 de junio de 2021 de: https:/ / nuso.org/ articulo/clase-media-reflexiones-sobre-los-malosusos-academicos-de-una-categoria/.

Auyero, Javier (2016). Pacientes del Estado. Ciudad Autónoma de Buenos Aires: Eudeba.

Auyero, Javier y Benzecry, Claudio (2016). La lógica práctica del dominio clientelista. Revista Mexicana de Ciencias Politicas y Sociales, 61(226), 221-246. DOI: 10.1016/S0185-1918(16)30009-5.

Azuela, Antonio (2006). Visionarios y pragmáticos. Aproximación sociológica al derecho ambiental. México: IISUNAM y Fontamara.

Barozet, Emmanuelle (2006). El valor histórico del pituto: clase media, integración y diferenciación social en Chile. Revista de sociología, 20, 69-96. Recuperado el 5 de junio de 2021 de: http:/ / www2.facso. uchile.cl/sociologia/docs/Barozet_ValorHistorico_ Pituto.pdf.

Bourdieu, Pierre. (1985). Espacio social y génesis de "las clases". Espacios, 2, 27-55.

Cravino, Cristina y Mutuberría Lazarini, Valeria (2012). Del piquete a la cooperativa de vivienda. La cooperativa como herramienta política y de trabajo autogestivo para la producción de viviendas. En Cravino, Cristina (Ed.), Construyendo barrios. Transformaciones territoriales a partir de los programas federales de vivienda en el AMBA (2004-2009) (pp. 309-349). Ciudad Autónoma de Buenos Aires: CICCUS-Ediciones UNGS.

Catenazzi, Andrea y Chiara, Magdalena (2017). La participación en la gestión: alcances y límites en su institucionalización. En Chiara, Magdalena y Di Virgilio, Mercedes (Eds.), Gestión de la política social. Conceptos y herramientas (pp. 201-214). Los Polvorines: Ediciones UNGS.

Carmona, Rodrigo y Martínez, Carlos (2013). El presupuesto participativo como herramienta de transformación social, política e institucional. Un balance en el escenario argentino reciente. Revista ABRA, 33(47), 26-36. Recuperado el 3 de junio de: https://www.revistas.una.ac.cr/index.php/abra/article/view/5585.

Cefai, Daniel (2012). ¿Qué es una arena pública? Algunas pautas para un acercamiento pragmático. En Cefai, Daniel y Joseph, Isaac. (Eds.), L'heritage du pragmatisme. Conflitsd'urbanité et épreuvesdecivisme (pp. 51-81). La Tour d'Aigues: Éditions de l'Aube.

De Certeau, Michel (1999). La invención de lo cotidiano (Tomo I). México: Universidad Iberoamericana/
ITESO/ Centro Francés de Estudios Mexicanos y Centroamericanos.

Del Río, Juan Pablo (2017). Crédito hipotecario, acceso al suelo y clase media en la implementación del Pro.Cre.Ar en la ciudad de La Plata. En Cravino, Cristina (Ed.), Detrás de los conflictos. Estudios sobre la desigualdad urbana en la Región Metropolitana de Buenos Aires (pp. 265-305). Los Polvorines: Ediciones UNGS.

Di Virgilio, Mercedes y Rodríguez, Carla (2013). Producción Social del Hábitat. Abordajes conceptuales, prácticas de investigación y experiencias en las principales ciudades del Cono Sur. Ciudad Autónoma de Buenos Aires: Café de las Ciudades.

Di Virgilio, Mercedes (2012). Participación social y organizaciones sociales en la implementación de políticas orientadas a la producción social del hábitat en el área metropolitana de Buenos Aires, Argentina. Revista SAAP: Sociedad Argentina de Análisis Politico, 6(1).

Garibotti, Belén, Girola, Florencia y Boroccioni, Luciana (2017). Ciudadanía y hábitat en la ciudad de Buenos Aires desde una perspectiva etnográfica. $R e^{-}$ vista Vivienda y Ciudad, 4, 7-20. Recuperado el 3 de junio de 2021 de: https:// revistas.unc.edu.ar/index.php/ReViyCi/article/view/19008.

Hine, Christine (2004). Etnografia virtual. Barcelona: Editorial UOC.

Girola, Florencia (2017). De la ciudadanía universal a la(s) ciudadanía(s) local(es). Inmediaciones de la comunicación, 12(1), 155-177. DOI: https://doi. org/10.18861/ic.2017.12.1.2671.

Kessler, Gabriel (2016). Presentación. Aportes para pensar el clientelismo sin prejuicios. En Vommaro, Gabriel y Combes, Hélène (Eds.), El clientelismo politico. Desde 1950 hasta nuestros días (pp. 9-16). Buenos Aires: Siglo xxi Editores.

Landau, Matías (2008a). Cuestión de ciudadanía, autoridad estatal y participación ciudadana. Revista Mexicana de Sociología, 70(1), 7-45.

Landau, Matías (2008b). La participación en las políticas públicas y los límites de la metáfora espacial. Política y cultura, 30, 67-89.

Latour, Bruno (1998). De la mediación técnica: filosofía, sociología y genealogía. En Domenech, Miquel y Tirado, Francisco (Eds.), Sociología asimétrica (pp. 249-307). Barcelona: Gedisa.

Martinez, Carlos (2018). La evolución del presupuesto participativo en la Argentina. En Carmona, Rodrigo y López Acotto, Alejando (Eds). El presupuesto participativo en la Argentina Transformaciones politicas, sociales y de gestión pública (pp. 33-47). Los Polvorines: Ediciones UNGS. 
Martínez, Carlos y Arena, Emiliano (2013). Experiencias y buenas prácticas en presupuesto participativo. Buenos Aires: Unicef.

Melé, Patrice (2016). ¿Qué producen los conflictos urbanos? En Carrión, Fernando y Erazo, Jaime (Eds.), El derecho a la ciudad en América Latina. Visiones desde la política (pp. 127-155). México: UNAM, PUEC, CIALC, IDRC/CRDI.

Moreno, Viviana (2012). La construcción del techo, el trabajo por las facciones políticas. Entramados relacionales en la implementación del Programa de Emergencia Habitacional. En Cravino, Cristina (Ed.), Construyendo barrios. Transformaciones territoriales a partir de los programas federales de vivienda en el AMBA (2004-2009) (pp. 253-307). Ciudad Autónoma de Buenos Aires: CICCUS-Ediciones UNGS.

Pagani, María Laura y Arce, María Eray (2008). El Presupuesto Participativo como política pública de participación ciudadana: Debilidades y fortalezas de la experiencia platense. En Cambios y continuidades sociales y políticas en Argentina y la región en las últimas décadas. Desafíos para el conocimiento social. V Jornadas de Sociología de la UNLP, La Plata, Argentina.

Perelmiter, Luisina (2007). ¿Es posible la debilidad estatal? Notas de investigación en torno de la construcción del Estado en política social. Papeles de trabajo, Año 1(2), 2-20.

Perelmiter, Luisina (2012). Incertidumbre, informalidad y juego político. Reflexiones sobre la circulación de autoridad en la vida interna del Estado argentino. VII Jornadas de Sociología, Universidad Nacional de La Plata, Argentina.

Perelmiter, Luisina (2016). Burocracia plebeya. La trastienda de la asistencia social en el Estado Argentino. San Martín: UNSAM.

Potocko, Alejandra (2015). Apuntes de la implementación de las políticas de vivienda desde los actores. El Programa Federal de Emergencia Habitacional en el barrio 2 de abril en Humahuaca (Jujuy, Argentina). Cuaderno urbano, 18(18), 111-139. DOI: http://dx.doi.org/10.30972/crn.1818264.

Ramella, Sonia (2012). Diseños institucionales de los presupuestos participativos en gobiernos locales de la República Argentina (Tesis de Maestría en Administración Pública). Universidad de Buenos Aires, Buenos Aires.

Ramírez Kuri, Patricia (2007). La ciudad, espacio de construcción de ciudadanía. Revista Enfoques, 7, 85107.

Rodríguez, María Carla (2004). Producción social del Hábitat, una perspectiva en construcción. En Cuenya, Beatriz, Fidel, Carlos y Herzer, Hilda (Eds.),
Fragmentos sociales. Problemas urbanos de la Argentina. Ciudad Autónoma de Buenos Aires: Siglo XxI.

Rodríguez, María Florencia (2013). Las formas pobres de hacer ciudad: un recorrido histórico sobre las modalidades de hábitat popular y su incidencia en la agenda estatal. Realidad económica, 273, 53-76.

Roffman, Alejandra (2007). Participación de la sociedad civil en políticas públicas: una tipología de mecanismos institucionales participativos. VI Conferencia Regional de ISTR para América Latina y El Caribe, Salvador de Bahía, Brasil.

Thomasz, Ana Gretel y Girola, María Florencia (2016). Una exploración antropológica sobre la problemática de la ciudadanía en el conjunto habitacional de Piedrabuena (Ciudad de Buenos Aires, Argentina). Revista de Antropología del Museo de Entre Ríos, 2(1), 46-61. Recuperado el 3 de junio de 2021 de: https://ri.conicet.gov.ar/handle/11336/106344.

Thompson, Edward (2012). La formación de la clase obrera en Inglaterra. Ciudad Autónoma de Buenos Aires: Capitán Swing. (Obra original publicada en 1963)

Valadés García, Bertín (2011). Conceptualizar el papel de las redes sociales en internet en movimientos sociales y acciones colectivas. Propuesta aplicada a lo digital. Razón y Palabra, 77. Recuperado el 5 de junio de 2021 de: https:/ / www.redalyc.org/ pdf/1995/199520010091.pdf.

Ventura, Violeta (2020a). Clases medias y producción de ciudad: un análisis de la implementación del PROCREAR en La Plata (2013-2015) desde las prácticas de su población beneficiaria (Tesis doctoral). Universidad Nacional de General Sarmiento, Los Polvorines, Argentina.

Ventura, Violeta (2020b). Juntarse para alejarse y reproducir la clase. Estrategias residenciales de las clases medias en los márgenes asignados por el mercado. El caso de la población beneficiaria del plan PROCREAR en la ciudad de La Plata (2013-2015), Argentina. Investigaciones Geográficas, 60, 83-100. DOI: https://doi.org/10.5354/07195370.2020 .58679 .

Vértiz, Francisco (2016). La intervención estatal en la producción de la ciudad. Conformación y orientación de la política urbana en el partido de La Plata (2003-2014) (Tesis doctoral). Universidad Nacional de La Plata, Argentina.

Vommaro, Gabriel y Combes, Hélène (2016). El clientelismo político. Desde 1950 hasta nuestros días. Ciudad Autónoma de Buenos Aires: Siglo xxi.

Zapata, María Cecilia (2017). La política habitacional porteña bajo la lupa. Ciudad Autónoma de Buenos Aires: Teseo Press. 
Ventura, Violeta (2021). Las clases medias y los desafíos de la participación: procesos de ciudadanización en la producción de ciudad (La Plata, Argentina. 2013-2015). Hábitat y Sociedad, 14, 223-241.

<https://doi.org/10.12795/HabitatySociedad.2021.i14.012>

$\bigcirc$ 


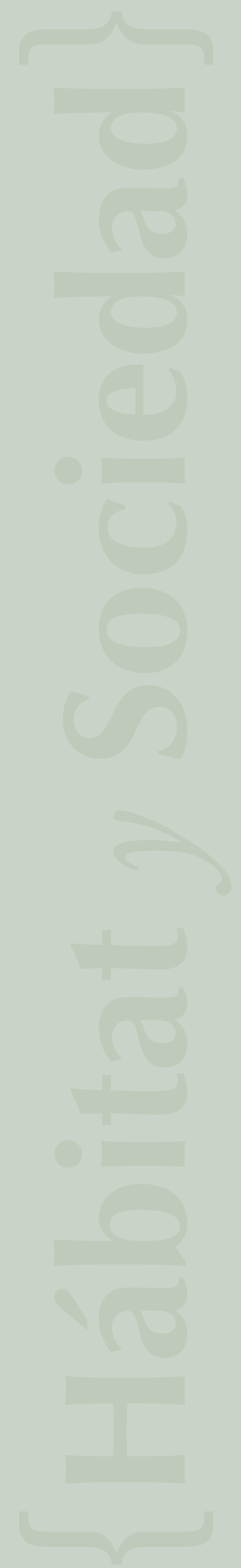

